\title{
Distinct epithelial growth factor receptor mutation profile in non-small-cell lung cancer patients from the Xuanwei area of China
}

\author{
YUN CHEN $^{1}$, LIJUAN YE ${ }^{1}$, REBECCA RONGRONG STANFORD ${ }^{2}$, DONGFANG ZHANG ${ }^{1}$, \\ $\mathrm{XINGSONG} \mathrm{ZHANG}^{1}$ and WANLI WEI ${ }^{1}$ \\ ${ }^{1}$ Department of Pathology, Yunnan Provincial Tumor Hospital, Kunming, Yunnan 650100, P.R. China; \\ ${ }^{2}$ Department of Life Sciences, Imperial College London, London SW7 2AZ, UK
}

Received November 30, 2015; Accepted February 25, 2016

DOI: $10.3892 / \mathrm{mco} .2016 .805$

\begin{abstract}
The Xuanwei county in China has a high incidence of lung cancer and related mortality. Previous studies have suggested that these cases may be associated with a distinctive pattern of mutations in the epithelial growth factor receptor (EGFR) gene. In this retrospective study, we investigated the mutation profile of EGFR in non-small-cell lung cancer (NSCLC) tissues from patients in Xuanwei, and the associated clinicopathological characteristics. Specimens from 258 consecutive patients with lung cancer ( 90 from Xuanwei and 168 from other areas of Yunnan province) were subjected to amplification refractory mutation system-polymerase chain reaction (ARMS-PCR) to detect EGFR mutations. In 67 specimens from Xuanwei, the results were confirmed by direct DNA sequencing for EGFR mutations. Immunohistochemistry (IHC) for the echinoderm microtubule-associated protein-like 4-anaplastic lymphoma kinase (EML4-ALK) fusion protein was performed on all specimens from Xuanwei. We observed that Xuanwei patients presented with distinctive clinicopathological characteristics, including female gender predominance, younger age, higher
\end{abstract}

Correspondence to: Professor Wanli Wei, Department of Pathology, Yunnan Provincial Tumor Hospital, 519 Kunzhou Road, Xishan, Kunming, Yunnan 650100, P.R. China

E-mail: 763756742@qq.com

Abbreviations: EGFR, epidermal growth factor receptor; ALK, anaplastic lymphoma kinase; EML4, echinoderm microtubule-associated protein-like 4; NSCLC, non-small-cell lung cancer; ARMS-PCR, amplification refractory mutation system polymerase chain reaction; IHC, immunohistochemistry; TKI, tyrosine kinase inhibitor; RT-PCR, reverse transcription polymerase chain reaction; FISH, fluorescence in situ hybridization; FFPE, formalin-fixed paraffin-embedded

Key words: lung cancer, epidermal growth factor receptor, echinoderm microtubule-associated protein-like 4-anaplastic lymphoma kinase, amplification refractory mutation system polymerase chain reaction, Xuanwei, environmental factors, household coal burning rate of lymph node metastasis, higher rate of adenocarcinoma histological classification and lower disease stage, and a low rate of the 'classical' mutations on EGFR exons 19 and 21 compared with non-Xuanwei patients (7.8 and $21.6 \%$ vs. 49.3 and $39.7 \%$, respectively; $\mathrm{P}<0.05$ for combined data). However, a significantly higher percentage of Xuanwei patients harbored co-mutation of EGFR exons 18 and 20 compared with non-Xuanwei patients (45.1 vs. $4.1 \%$, respectively; $\mathrm{P}<0.0001$ ). Specimens from 2 Xuanwei patients $(2.2 \%)$ were positive for the EML4-ALK fusion protein; by IHC, neither harbored EGFR mutations. There was no obvious association between EGFR mutations and disease stage or lymph node involvement. Thus, NSCLC patients in Xuanwei presented with a unique EGFR profile of high rates of co-mutation of exons 18 and 20, and low rates of exon 19 or 21 mutations when compared with patients from other areas in the same province, whereas only few of the tumors from Xuanwei patients expressed the EML4-ALK oncogene.

\section{Introduction}

Lung cancer is the leading cause of cancer-related mortality worldwide, with an incidence of 1.4 million per year and a mortality rate of 1.2 million per year $(1,2)$. Non-small-cell lung cancer (NSCLC) accounts for $\sim 80 \%$ of all lung cancer cases, and understanding the underlying mechanisms is crucial for identifying effective means of prevention and treatment (3).

Overexpression of epidermal growth factor receptor(EGFR) is observed in various malignancies, including lung cancer (4). EGFR activation is related to cell proliferation and survival via complex intracellular signalling pathways. The EGFR tyrosine kinase pathway, in particular, has become an optimal therapeutic target. EGFR-tyrosine kinase inhibitors (EGFR-TKIs), such as gefitinib and erlotinib, have exhibited encouraging results in terms of clinical activity against NSCLCs harboring activating EGFR mutations $(5,6)$.

Xuanwei county has the highest lung cancer incidence and mortality rates in China, in men as well as in women. Environmental factors are known to play a role in cancer incidence, and indoor air pollution from the use of smoky coal for household purposes has been suggested to be the cause of the 
high rates of lung cancer in Xuanwei, particularly in non-smoking female patients. A previous study including a limited patient number demonstrated that non-smoking female lung cancer patients in Xuanwei exhibit different EGFR mutation patterns compared with the patterns seen elsewhere in Asia (7).

The echinoderm microtubule-associated proteinlike 4-anaplastic lymphoma kinase (EML4-ALK) oncogene, which was first identified by researchers from Japan, was found to be active in $2.9-11.4 \%$ of NSCLC patients in China (8-11) and is often present in adenocarcinomas in non-smokers. To the best of our knowledge, no study has yet been conducted to determine the incidence of EML4-ALK fusion protein in Xuanwei patients.

In this retrospective study, we screened 258 resection samples from lung cancer patients (90 from Xuanwei and 168 from other regions in the same province) to characterize the EGFR expression and mutation profiles and their association with EML4-ALK. A better understanding of the specific mutations present in the patients from this region may lead to more effective targeted therapeutic interventions at earlier stages of the disease.

\section{Materials and methods}

Clinical data. This retrospective study was conducted on specimens stored in the tissue registry of the Yunnan Provincial Tumor Hospital, with the approval of the Institutional Review Board. Cancer tissues were obtained from consecutive NSCLC patients who underwent pulmonary resection at the Department of Thoracic Surgery of our hospital between February, 2011 and February, 2014.

Amplification refractory mutation system polymerase chain reaction (ARMS-PCR). Genomic DNA from 3x5-mm formalin-fixed, paraffin-embedded (FFPE) sections was isolated manually using a QIAamp DNA FFPE Tissue kit (Qiagen, Hilden, Germany) in accordance with the manufacturer's instructions. Polymorphisms in exons 18 (G719X), 19 (S768I), 20 (G779C, S768I, L858R, V774M) and 21 (L861Q and L858R) were detected with the ARMS-PCR technique. DNA amplification was performed using specific nested primer sets for each polymorphism. PCR amplifications were performed in a total volume of $25 \mu \mathrm{l}$ containing $100 \mathrm{ng}$ genomic DNA, 1X PCR buffer, 10 pmol of each primer, $10 \mathrm{nmol}$ of each deoxyribonucleotide triphosphate, $1.5 \mathrm{mM}$ $\mathrm{Mg}^{2+}$, and $1 \mathrm{U}$ TaqDNA polymerase. The PCR conditions were as follows: Initial denaturation step $\left(94^{\circ} \mathrm{C}\right.$ for $\left.2 \mathrm{~min}\right)$; 10 cycles of denaturation $\left(94^{\circ} \mathrm{C}\right.$ for $\left.15 \mathrm{sec}\right)$ and annealing/extension $\left(65^{\circ} \mathrm{C}\right.$ for $\left.60 \mathrm{sec}\right)$, followed by 20 cycles of denaturation $\left(94^{\circ} \mathrm{C}\right.$ for $\left.10 \mathrm{sec}\right)$, annealing $\left(62^{\circ} \mathrm{C}\right.$ for $\left.50 \mathrm{sec}\right)$ and extension $\left(72^{\circ} \mathrm{C}\right.$ for $\left.30 \mathrm{sec}\right)$. The PCR products were separated in a $2 \%$ agarose gel and visualized with ethidium bromide staining and ultraviolet illumination with a gel documentation system (Gel Doc 2000; Bio-Rad, Hercules, CA, USA).

Direct DNA sequencing. To verify the ARMS-PCR results, DNA samples obtained from 67 Xuanwei specimens were amplified, purified and sequenced using BigDye Terminator v3.1 on an ABI 3100 Genetic Analyzer (both from Applied Biosystems, Foster City, CA, USA).
Immunohistochemistry (IHC). All Xuanwei samples were subjected to IHC to detect the EML4-ALK fusion protein. IHC was performed on 4- $\mu \mathrm{m}$ FFPE tissue sections placed on silane-coated slides using the 5A4 anti-ALK primary antibody in the ALK Detection kit (Nichirei Bioscience, Tokyo, Japan) (12). Tumor cells that stained more strongly in the cytoplasm compared with negative control cells, were defined as IHC-positive. Semi-quantitative assessment was performed by estimating the percentage of IHC-positive tumor cells. ALK IHC scores were assigned using the iAEP method (iScore) as follows: 0 , no stained cells; $1,0-50 \%$ stained tumor cells; $2,50-80 \%$ stained tumor cells or $>80 \%$ stained tumor cells with marked variability of staining intensity ("checkerboard pattern'); and 3,>80\% stained tumor cells without marked variability of staining intensity.

Fluorescent in situ hybridization (FISH). Specimens positive for the EML4-ALK fusion protein by IHC were confirmed by FISH performed on the 4- $\mu \mathrm{m}$ FFPE tissue sections using the Vysis ALK Break Apart FISH Probe kit (Vysis LSI ALK Dual Color Break Apart rearrangement probe; Abbott Molecular, Abbott Park, IL, USA) in accordance with the manufacturer's instructions. At least 50 representative tumor cells were counted. When $\geq 15 \%$ of the tumor cells exhibited separate green and red signals or an isolated (single) red signal, the sample was considered to contain an ALK gene rearrangement. All other samples were classified as ALK FISH-negative.

Statistical analysis. Statistical analyses were performed using SPSS software, version 16.0 (SPSS Inc., Chicago, IL, USA). Data were subjected to the Pearson's Chi-square and Fisher's exact tests. $\mathrm{P}<0.05$ was considered to indicate statistically significant differences.

\section{Results}

Patient characteristics. Cancer tissues from 258 consecutive NSCLC patients (123 men and 135 women) who had undergone pulmonary resection at the Department of Thoracic Surgery of our hospital between February, 2011 and February, 2014, were obtained from the tissue registry of our institution. Of the 258 patients, 90 were from Xuanwei (32 men and 58 women) and 158 were from non-Xuanwei areas in the same province (91 men and 77 women). Patient demographic and pathological characteristics are summarized in Table I. There were significantly more women $(\mathrm{P}<0.0059$, Fisher's exact test $)$ and younger patients $(\mathrm{P}<0.0488$, Fisher's exact test $)$ in the Xuanwei group compared with the non-Xuanwei control group. Lymph node metastasis was significantly more common in the Xuanwei cohort $(\mathrm{P}<0.0001)$. Furthermore, more Xuanwei patients had tumors characterized as adenocarcinomas $(\mathrm{P}<0.0031$, Chi-square test) and at lower stages $(\mathrm{P}<0.0001$, Chi-square test). However, the distribution of patients for smoking status was similar between the two groups.

EGFR mutations in Xuanwei and non-Xuanwei NSCLC patients. Among Xuanwei and non-Xuanwei lung cancer patients, $51(57 \%)$ and $73(43 \%)$ harbored EGFR mutations, respectively (Table II). The non-Xuanwei cohort exhibited a high frequency of deletion mutations in exon $19(n=36,49.3 \%$ 
Table I. Patient demographic and characteristics tumor clinicopathology.

\begin{tabular}{|c|c|c|c|c|c|}
\hline \multirow[b]{2}{*}{ Characteristics } & \multicolumn{2}{|c|}{ Xuanwei (n=90) } & \multicolumn{2}{|c|}{ Non-Xuanwei $(n=158)$} & \multirow[b]{2}{*}{ P-value } \\
\hline & $\mathrm{n}$ & $\%$ & $\mathrm{n}$ & $\%$ & \\
\hline \multicolumn{6}{|l|}{ Gender } \\
\hline Male & 32 & 35.6 & 91 & 54.38 & \multirow[t]{2}{*}{0.0059} \\
\hline Female & 58 & 64.4 & 77 & 45.8 & \\
\hline \multicolumn{6}{|l|}{ Age (years) } \\
\hline$\leq 60$ & 69 & 76.7 & 108 & 64.3 & \multirow[t]{2}{*}{0.0488} \\
\hline$>60$ & 21 & 23.3 & 60 & 35.7 & \\
\hline \multicolumn{6}{|l|}{ Smoking status } \\
\hline Yes & 21 & 23.3 & 49 & 29.2 & \multirow[t]{2}{*}{0.3785} \\
\hline No & 69 & 76.7 & 119 & 70.8 & \\
\hline \multicolumn{6}{|c|}{ Lymph node metastasis } \\
\hline Yes & 52 & 57.8 & 23 & 13.7 & \multirow[t]{2}{*}{$<0.0001$} \\
\hline No & 38 & 42.2 & 145 & 86.3 & \\
\hline \multicolumn{6}{|l|}{ Histology } \\
\hline Ad & 86 & 95.6 & 140 & 83.3 & \multirow[t]{3}{*}{0.0031} \\
\hline $\mathrm{SCC}$ & 3 & 3.3 & 28 & 16.7 & \\
\hline $\mathrm{Sa}$ & 1 & 1.1 & 0 & & \\
\hline \multicolumn{6}{|l|}{ Stage } \\
\hline I & 38 & 42.2 & 23 & 13.7 & \multirow[t]{4}{*}{$<0.0001$} \\
\hline II & 18 & 20.0 & 15 & 8.9 & \\
\hline III & 11 & 12.2 & 20 & 11.9 & \\
\hline IV & 23 & 25.6 & 110 & 65.5 & \\
\hline
\end{tabular}

P-values were determined with the Chi-square or Fisher's exact test. Bold print indicates statistical significance. Ad, adenocarcinoma; SCC, squamous cell carcinoma; Sa, sarcomatoid carcinoma.

Table II. Characterisation and comparison of EGFR mutations in Xuanwei and non-Xuanwei NSCLC patients.

\begin{tabular}{|c|c|c|c|c|c|c|}
\hline \multirow[b]{2}{*}{ Exon } & \multirow[b]{2}{*}{ Mutation } & \multicolumn{2}{|c|}{ Xuanwei } & \multicolumn{2}{|c|}{ Non-Xuanwei } & \multirow[b]{2}{*}{ P-value } \\
\hline & & Cases & $\%$ & Cases & $\%$ & \\
\hline 18 & G719X & 4 & 7.8 & 1 & 1.4 & NA \\
\hline \multirow[t]{2}{*}{$18+20$} & G719X+G779C & 1 & 2.0 & - & & NA \\
\hline & G719X+S768I & 23 & 45.1 & 3 & 4.1 & $<0.0001$ \\
\hline $18+21$ & G719X+L861Q & 1 & 2.0 & 1 & 1.4 & NA \\
\hline 19 & Deletion & 4 & 7.8 & 36 & 49.3 & $<0.0001$ \\
\hline $19+21$ & Deletion+L858R & 1 & 2.0 & - & & NA \\
\hline \multirow[t]{3}{*}{20} & P772_H773 insertion & 1 & 2.0 & - & & NA \\
\hline & S768I & 2 & 3.9 & 2 & 2.7 & NA \\
\hline & S768I+V774M insertion & 2 & 3.9 & 1 & 1.4 & NA \\
\hline $20+21$ & S768I+L858R & 1 & 2.0 & - & & NA \\
\hline \multirow[t]{2}{*}{21} & L858R & 10 & 19.6 & 27 & 37.0 & 0.1496 \\
\hline & L861Q & 1 & 2.0 & 2 & 2.7 & \\
\hline Total & & 51 & 100.0 & 73 & 100.0 & \\
\hline
\end{tabular}

NA, not assessed due to small number of specimens. P-values were determined using the Fisher's exact test by comparing the distribution of patients with and without indicated mutations between the Xuanwei and non-Xuanwei regions. EGFR, epidermal growth factor receptor. 

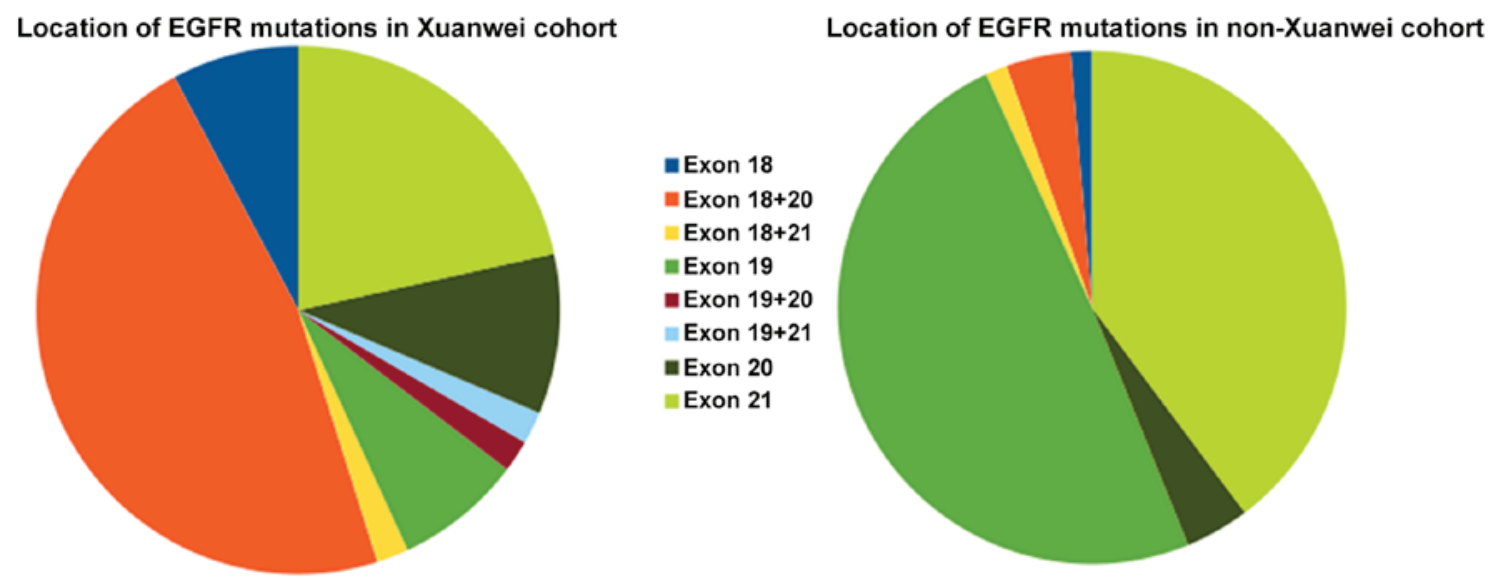

Figure 1. Distribution of EGFR mutations. Exon $18+20$ co-mutations (orange) were most common in the Xuanwei cohort, whereas in the non-Xuanwei cohort, mutations in exons 19 and 21, which are considered to be 'classical' mutations, were the most common, while mutations in exons 18, 20 and 18+20 occurred infrequently. EGFR, epidermal growth factor receptor.

of total mutations) and point mutations in exon $21(\mathrm{n}=29$, $39.7 \%$ of total mutations). These mutations were identified in a significantly smaller percentage of Xuanwei patients (exon 19: $\mathrm{n}=4,7.8 \%$ of total mutations; and exon $21: \mathrm{n}=11,21.6 \%$ of total mutations) (Fig. 1). However, the Xuanwei cohort had more mutations in the combination of exons 18 G719X and 20 S768I ( $n=23$, or $45.1 \%$ of total mutations), whereas mutations in this combination were rare in the non-Xuanwei cohort $(n=3 / 73,4.1 \%)$. Using the Fisher's exact test, the distribution of patients with and without specified mutations between the Xuanwei and non-Xuanwei regions was found to be significantly different for deletion mutations in exon 19 and double mutations in exons 18 and 20 (Table II).

Differences in exonal localization of EGFR mutations between Xuanwei and non-Xuanwei patients. We further compared the exonal localization of EGFR mutations (Table III), and found significant differences for exons 18/20, as well as for the combination of exons 19 and 21 or the combination of exons 18 and 20 , the latter mutations being less frequently detected in general lung cancer patients (13).

Association between clinicopathological characteristics and EGFR events in Xuanwei and non-Xuanwei patients. The distributions of EFGR mutations were similar by age, histology, and lymph node involvement (Table IV). However, Xuanwei patients were significantly more likely to be non-smokers rather than smokers $(\mathrm{P}<0.05)$, which was not the case for non-Xuanwei patients (Table IV). In the Xuanwei as well as the non-Xuanwei cohort, the distribution of patients was significantly different between the two genders $(\mathrm{P}<0.05)$, in accordance with a previous study (8).

Detection of EGFR mutations with the ARMS and direct sequencing methods. Direct DNA sequencing of a subset of samples from the Xuanwei cohort $(n=67)$ confirmed almost all the ARMS results, with the exception of one deletion mutation in exon 19. The sequencing also identified 4 point mutations in exon 20 [P772-H773 (insGNP), S768I, V774M and G779C] (Table V), which had not been previously reported in the literature.
Table III. Differences in exonal localization of EGFR mutations between Xuanwei and non-Xuanwei patients.

\begin{tabular}{|c|c|c|c|c|c|}
\hline \multirow{2}{*}{$\begin{array}{l}\text { Exon } \\
19\end{array}$} & \multirow{2}{*}{$\begin{array}{c}\text { Mutation } \\
\text { Yes }\end{array}$} & \multirow{2}{*}{$\begin{array}{c}\text { Xuanwei } \\
5\end{array}$} & \multirow{2}{*}{$\begin{array}{c}\begin{array}{c}\text { Non- } \\
\text { Xuanwei }\end{array} \\
36\end{array}$} & \multicolumn{2}{|c|}{ P-value } \\
\hline & & & & 0.0003 & 0.0005 \\
\hline & No & 85 & 122 & & \\
\hline \multirow[t]{2}{*}{21} & Yes & 14 & 30 & 0.6046 & \\
\hline & No & 76 & 128 & & \\
\hline \multirow[t]{2}{*}{18} & Yes & 35 & 5 & 0.0001 & 0.0001 \\
\hline & No & 55 & 153 & & \\
\hline \multirow[t]{2}{*}{20} & Yes & 30 & 6 & 0.0001 & \\
\hline & No & 60 & 152 & & \\
\hline
\end{tabular}

${ }^{\mathrm{a} F i s h e r ' s ~ e x a c t ~ t e s t . ~ E G F R, ~ e p i d e r m a l ~ g r o w t h ~ f a c t o r ~ r e c e p t o r . ~}$

EML4-ALK detection by IHC and FISH. Two specimens from Xuanwei patients were found to be positive for EML4-ALK by IHC (Fig. 2), and this result was confirmed by FISH (Fig. 3). The patients who were positive for EML4-ALK did not harbor EGFR mutations (data not shown).

\section{Discussion}

Xuanwei county in the province of Yunnan, located in Southwest China, is known to have very high rates of lung cancer compared with the general population of China (7). In order to gain a better understanding of the potential drug sensitivities within this population, we screened samples from our tissue registry for EGFR mutations, a known cause of NSCLC. Our large sample consisted of tissue from 258 consecutive lung cancer patients, 90 from Xuanwei and 168 from other areas of Yunnan. To the best of our knowledge, this study is the first comprehensive profile of EGFR mutations in the Xuanwei area using patients from the same province as controls.

EGFR mutation rates were found to be higher in specimens from Xuanwei compared with other areas. These numbers are marginally higher compared with those for the general Asian 
Table IV. Association between clinicopathological characteristics and EGFR events in Xuanwei and non-Xuanwei lung cancer patients.

\begin{tabular}{|c|c|c|c|c|c|c|c|c|c|c|}
\hline \multirow[b]{3}{*}{ Characteristics } & \multicolumn{5}{|c|}{ Xuanwei patients } & \multicolumn{5}{|c|}{ Non-Xuanwei patients } \\
\hline & \multicolumn{2}{|c|}{ Wild-type } & \multicolumn{2}{|c|}{ EGFR mutation } & \multirow[b]{2}{*}{ P-value } & \multicolumn{2}{|c|}{ Wild-type } & \multicolumn{2}{|c|}{ EGFR mutation } & \multirow[b]{2}{*}{ P-value } \\
\hline & $\mathrm{n}$ & $\%$ & $\mathrm{n}$ & $\%$ & & $\mathrm{n}$ & $\%$ & $\mathrm{n}$ & $\%$ & \\
\hline Age (years) & & & & & 0.80 & & & & & 0.07 \\
\hline$\leq 60$ & 29 & 74.4 & 40 & 78.4 & & 67 & 70.5 & 41 & 56.2 & \\
\hline$>60$ & 10 & 25.6 & 11 & 21.6 & & 28 & 29.5 & 32 & 43.8 & \\
\hline Gender & & & & & $<0.01$ & & & & & $<0.02$ \\
\hline Male & 20 & 51.3 & 12 & 23.5 & & 59 & 62.1 & 32 & 43.8 & \\
\hline Female & 19 & 48.7 & 39 & 76.5 & & 36 & 37.9 & 41 & 56.2 & \\
\hline Smoking history & & & & & $<0.02$ & & & & & 0.17 \\
\hline Yes & 14 & 35.9 & 7 & 13.7 & & 32 & 33.7 & 17 & 23.3 & \\
\hline No & 25 & 64.1 & 44 & 86.3 & & 63 & 66.3 & 56 & 76.7 & \\
\hline Histology & & & & & $<0.03$ & & & & & $<0.001$ \\
\hline Adenocarcinoma & 35 & 89.7 & 51 & 100.0 & & 71 & 74.7 & 69 & 94.5 & \\
\hline Others & 4 & 10.3 & 0 & & & 24 & 25.3 & 4 & 5.5 & \\
\hline Stage & & & & & 1.00 & & & & & 1.00 \\
\hline I-II & 24 & 61.5 & 32 & 62.7 & & 22 & 23.2 & 16 & 21.9 & \\
\hline III-IV & 15 & 39.5 & 19 & 37.3 & & 73 & 76.8 & 57 & 78.1 & \\
\hline Lymph nodes & & & & & 1.00 & & & & & 0.38 \\
\hline Yes & 23 & 59.0 & 29 & 56.9 & & 11 & 11.6 & 12 & 16.4 & \\
\hline No & 16 & 41.0 & 22 & 43.1 & & 84 & 88.4 & 61 & 83.6 & \\
\hline
\end{tabular}

EGFR, epidermal growth factor receptor.

population (8). In addition to the high frequency of occurrence, Xuanwei patients carrying EGFR mutations also exhibit distinct demographic and pathological characteristics. EGFR mutations are more likely detected in women and younger patients in the Xuanwei area compared with non-Xuanwei areas. Clinicopathologically, Xuanwei patients carrying EGFR mutations are more likely to be classified as adenocarcinomas or have lymph node metastasis, but less likely to be diagnosed at more advanced stages. These results suggest that the factors causing EGFR mutations and subsequent pathogenesis are likely different between the two patient groups.

Consistent with previous studies $(7,8)$, we found reciprocal patterns of mutations in patients from different regions: Non-Xuanwei patients most frequently exhibited deletion mutations in exon 19 and L858R point mutations in exon 21 (the 'classical' mutations), whereas the majority of mutations in Xuanwei patients were in exon 18. However, we also found a strikingly higher number of co-mutations in exon 18 (mainly G719X) and exon 20 (S768I) in Xuanwei patients when compared with non-Xuanwei patients, a result that has not been previously reported. Intriguingly, 18 of the 23 patients with G719X and S768I double mutations were women (data not shown). This is likely due to the exposure of women to increased household coal burning, since the women in the Xuanwei area are more likely to stay at home doing household work (7). These distinctive molecular characteristics in EGFR
Table V. Number of EGFR mutations found with the ARMS and direct sequencing methods.

\begin{tabular}{lcccc}
\hline Method & Exon 18 & Exon 19 & Exon 20 & Exon 21 \\
\hline ARMS & 24 & 4 & 20 & 10 \\
Direct & 24 & 3 & 24 & 10 \\
sequencing & & & & \\
\hline
\end{tabular}

EGFR, epidermal growth factor receptor; ARMS, amplification refractory mutation system.

mutations observed in Xuanwei patients may have contributed to the abovementioned clinicopathological characteristics that are specific to this group of patients.

Direct DNA sequencing confirmed almost all EGFR mutations identified by ARMS. The only exception was a deletion mutation in exon 19, which may have been the result of loading an insufficient amount of sample. Direct DNA sequencing also identified 4 additional point mutations (Table V). Thus, direct DNA sequencing described a more detailed mutation profile compared with ARMS in our study.

The EML4-ALK fusion protein was positive in $2.2 \%$ of Xuanwei patients (2 of 90). This is lower compared with the 


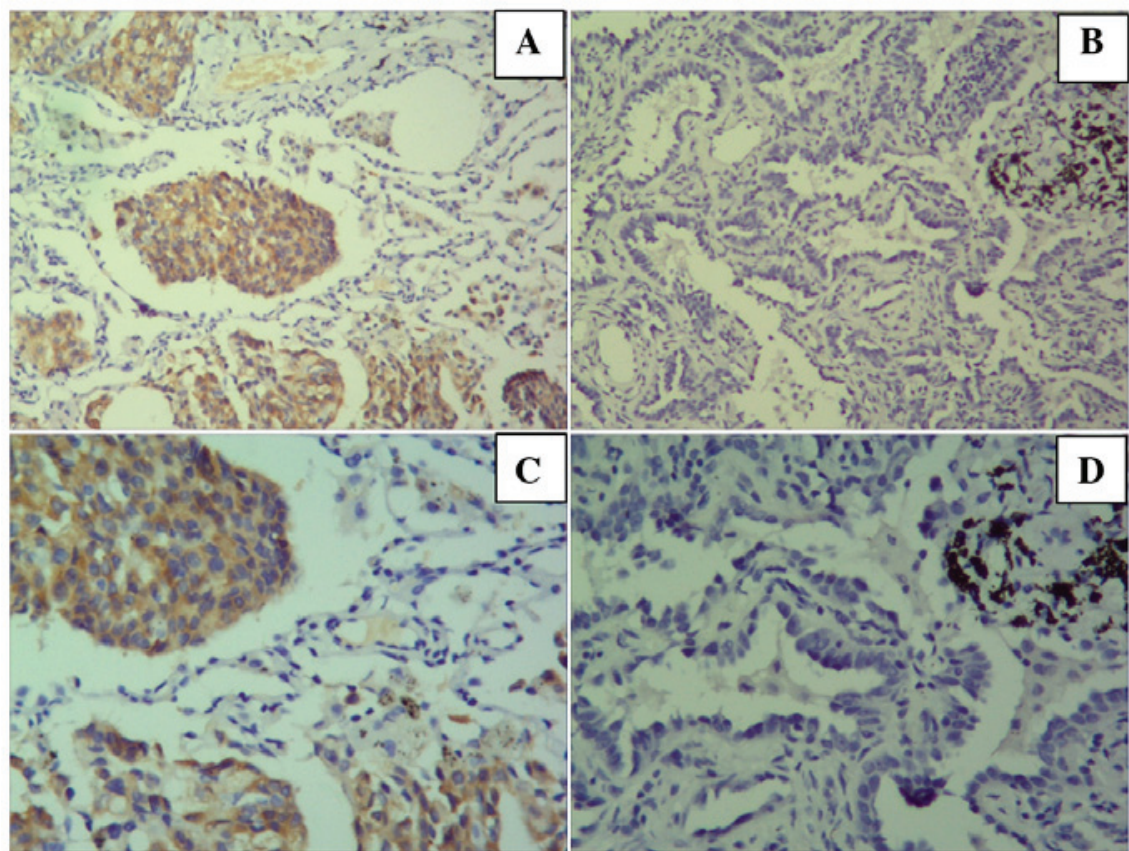

Figure 2. Immunohistochemistry for anaplastic lymphoma kinase (ALK). (A and C) A tumor sample with an iScore of 3 (see Materials and methods) was considered to be positive for ALK. (B and D) A sample with an iScore of 0 was considered to be negative for ALK. Magnification, x100 for (A and B), x200 for (C and D). Brown color, immunopositivity for ALK.
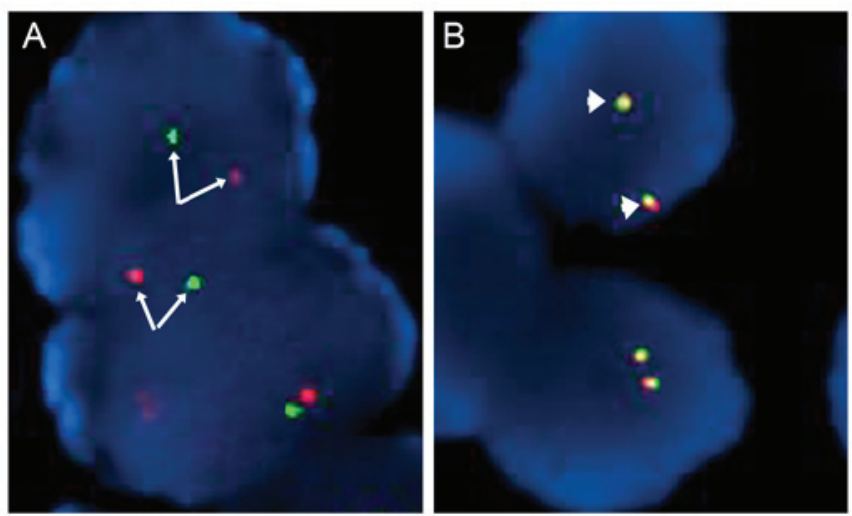

Figure 3. Fluorescent in situ hybridization assay showing gene rearrangement in an (A) echinoderm microtubule-associated protein-like 4-anaplastic lymphoma kinase (EML4-ALK)-positive and (B) EML4-ALK-negative carcinoma tissue. (A) ALK gene rearrangements are indicated by separated red and green signals (pair of arrows) labelled by two probes flanking the ALK breaking point in a single nucleus. (B) In normal nuclei, red and green fluorescent dots are colocalized or separated by less than two signal diameters apart (arrowheads).

percentage reported for other Asian regions (10). It is possible that the increased lung cancer incidence in the Xuanwei area is exclusively associated with EGFR mutations, thus resulting in the lower prevalence of EML4-ALK fusions. None of the specimens that were positive for the EML4-ALK fusion protein harboured any EGFR mutations. This is consistent with a previous study suggesting that EML4-ALK and EGFR mutations are independent events and are mutually exclusive (14). Due to the small number of EML4-ALK-positive specimens in this study ( 2 samples out of 90), further investigation is required to draw any conclusions regarding this finding in the
Xuanwei population, but would suggest that treatment of this group with crizotinib is contraindicated.

In conclusion, this study provides a comprehensive profile of EGFR gene mutations in Xuanwei patients and patients from other areas in Yunnan province. Particularly since a high percentage of the Xuanwei patients were never smokers, a status associated with EGFR mutations (15), it offers an excellent model to study environmental or genetic factors, or interactions between them, in lung cancer biology. Mutations in the EGFR are known to either sensitize tumors to TKIs, or to make them refractory to such treatments (16). Furthermore, the efficacy of EGFR-TKI and ALK inhibitors is known to decrease in some initially responsive patients. The detailed evaluation of mutations found in the Xuanwei subpopulation of NSCLC patients presented in this study holds the potential for improvements in targeted therapies. Further studies in this group, regarding responsiveness to TKIs and other targeted therapies, are required.

\section{References}

1. Parkin DM, Bray F, Ferlay J and Pisani P: Global cancer statistics, 2002. CA Cancer J Clin 55: 74-108, 2005.

2. Jemal A, Siegel R, Ward E, Murray T, Xu J and Thun MJ: Cancer statistics, 2007. CA Cancer J Clin 57: 43-66, 2007.

3 . Buettner R, Wolf J and Thomas RK: Lessons learned from lung cancer genomics: The emerging concept of individualized diagnostics and treatment. J Clin Oncol 31: 1858-1865, 2013.

4. Normanno N, Maiello MR and De Luca A: Epidermal growth factor receptor tyrosine kinase inhibitors (EGFR-TKIs): Simple drugs with a complex mechanism of action? J Cell Physiol 194: 13-19, 2003.

5. Maemondo M, Inoue A, Kobayashi K, Sugawara S, Oizumi S, Isobe H, Gemma A, Harada M, Yoshizawa H, Kinoshita I, et al; North-East Japan Study Group: Gefitinib or chemotherapy for non-small-cell lung cancer with mutated EGFR. N Engl J Med 362: 2380-2388, 2010. 
6. Rosell R, Carcereny E, Gervais R, Vergnenegre A, Massuti B, Felip E, Palmero R, Garcia-Gomez R, Pallares C, Sanchez JM, et al; Spanish Lung Cancer Group in collaboration with Groupe Français de Pneumo-Cancérologie and Associazione Italiana Oncologia Toracica: Erlotinib versus standard chemotherapy as first-line treatment for European patients with advanced EGFR mutation-positive non-small-cell lung cancer (EURTAC) A multicentre, open-label, randomised phase 3 trial. Lancet Oncol 13: 239-246, 2012.

7. Hosgood HD III, Pao W, Rothman N, Hu W, Pan YH, Kuchinsky K, Jones KD, Xu J, Vermeulen R, Simko J, et al: Driver mutations among never smoking female lung cancer tissues in China identify unique EGFR and KRAS mutation pattern associated with household coal burning. Respir Med 107: $1755-1762,2013$.

8. Shigematsu H and Gazdar AF: Somatic mutations of epidermal growth factor receptor signaling pathway in lung cancers. Int J Cancer 118: 257-262, 2006.

9. Sun Y, Ren Y, Fang Z, Li C, Fang R, Gao B, Han X, Tian W, Pao W, Chen $\mathrm{H}$, et al: Lung adenocarcinoma from East Asian never-smokers is a disease largely defined by targetable oncogenic mutant kinases. J Clin Oncol 28: 4616-4620, 2010.

10. Wong DW, Leung EL, So KK, Tam IY, Sihoe AD, Cheng LC, Ho KK, Au JS, Chung LP and Pik Wong M; University of Hong Kong Lung Cancer Study Group: The EML4-ALK fusion gene is involved in various histologic types of lung cancers from nonsmokers with wild-type EGFR and KRAS. Cancer 115: $1723-1733,2009$
11. Rikova K, Guo A, Zeng Q, Possemato A, Yu J, Haack H, Nardone J, Lee K, Reeves C, Li Y, et al: Global survey of phosphotyrosine signaling identifies oncogenic kinases in lung cancer. Cell 131: 1190-1203, 2007.

12. Takeuchi K, Choi YL, Togashi Y, Soda M, Hatano S, Inamura K, Takada S, Ueno T, Yamashita Y, Satoh Y, et al: KIF5B-ALK, a novel fusion oncokinase identified by an immunohistochemistry-based diagnostic system for ALK-positive lung cancer. Clin Cancer Res 15: 3143-3149, 2009.

13. Siegelin MD and Borczuk AC: Epidermal growth factor receptor mutations in lung adenocarcinoma. Lab Invest 94: 129-137, 2014.

14. Wang Y, Wang S, Xu S, Qu J and Liu B: Clinicopathologic features of patients with non-small cell lung cancer harboring the EML4-ALK fusion gene: A meta-analysis. PLoS One 9: e110617, 2014.

15. Pao W, Miller V, Zakowski M, Doherty J, Politi K, Sarkaria I, Singh B, Heelan R, Rusch V, Fulton L, et al: EGF receptor gene mutations are common in lung cancers from 'never smokers' and are associated with sensitivity of tumors to gefitinib and erlotinib. Proc Natl Acad Sci USA 101: 13306-13311, 2004.

16. Sharma SV, Bell DW, Settleman J and Haber DA: Epidermal growth factor receptor mutations in lung cancer. Nat Rev Cancer 7: 169-181, 2007. 